\title{
Article \\ Separation and Efficient Recovery of Lithium from Spent Lithium-Ion Batteries
}

\author{
Eva Gerold *, Stefan Luidold and Helmut Antrekowitsch
}

Citation: Gerold, E.; Luidold, S.; Antrekowitsch, H. Separation and Efficient Recovery of Lithium from Spent Lithium-Ion Batteries. Metals 2021, 11, 1091. https://doi.org/ $10.3390 /$ met11071091

Academic Editor: Alexandre Chagnes

Received: 2 June 2021

Accepted: 6 July 2021

Published: 8 July 2021

Publisher's Note: MDPI stays neutral with regard to jurisdictional claims in published maps and institutional affiliations.

Copyright: (C) 2021 by the authors Licensee MDPI, Basel, Switzerland. This article is an open access article distributed under the terms and conditions of the Creative Commons Attribution (CC BY) license (https:/ / creativecommons.org/licenses/by/ $4.0 /)$.
Chair of Nonferrous Metallurgy of Montuniversitaet Leoben, 8700 Leoben, Austria; stefan.luidold@unileoben.ac.at (S.L.); helmut.antrekowitsch@unileoben.ac.at (H.A.)

* Correspondence: eva.gerold@unileoben.ac.at; Tel.: +43-3842-402-5207
Abstract: The consumption of lithium has increased dramatically in recent years. This can be primarily attributed to its use in lithium-ion batteries for the operation of hybrid and electric vehicles. Due to its specific properties, lithium will also continue to be an indispensable key component for rechargeable batteries in the next decades. An average lithium-ion battery contains $5-7 \%$ of lithium. These values indicate that used rechargeable batteries are a high-quality raw material for lithium recovery. Currently, the feasibility and reasonability of the hydrometallurgical recycling of lithium from spent lithium-ion batteries is still a field of research. This work is intended to compare the classic method of the precipitation of lithium from synthetic and real pregnant leaching liquors gained from spent lithium-ion batteries with sodium carbonate (state of the art) with alternative precipitation agents such as sodium phosphate and potassium phosphate. Furthermore, the correlation of the obtained product to the used type of phosphate is comprised. In addition, the influence of the process temperature (room temperature to boiling point), as well as the stoichiometric factor of the precipitant, is investigated in order to finally enable a statement about an efficient process, its parameter and the main dependencies.

Keywords: recycling; lithium-ion batteries; lithium recovery; precipitation; hydrometallurgy; critical element

\section{Introduction}

Lithium differentiates itself from all other alkali metals due to its special properties, such as the high energy density by weight and the electrochemical potential of $-3.045 \mathrm{~V}$, making this element useful for several applications, including rechargeable lithium-ion batteries [1]. The lithium market has developed very dynamically in recent years. One of the reasons can be identified in the high expectations of the industry regarding the field of application of rechargeable batteries and in particular e-mobility. The storage of renewable energy also plays an important role in this context [2]. Besides these main areas of usage, lithium is also employed in ceramic and glass manufacture and in aluminum production (see Figure 1) [1]. Lithium carbonate $\left(\mathrm{Li}_{2} \mathrm{CO}_{3}\right)$ is one of the most important compounds of this alkali element and is often applied in medicine in addition to the areas already mentioned [3-8].

The consumption of lithium has increased dramatically in recent years [5,9-12]. This is primarily caused by its use in lithium-ion batteries for the operation of hybrid and electric vehicles [13-15]. Further developments in the battery sector, such as lithium-sulfur batteries, continue to lead to an immense consumption of lithium in this area $[16,17]$. Due to its specific properties, lithium will continue to be an essential component for rechargeable batteries in the next decades. Therefore, very high growth rates are expected in future years. Depending on the scenario, the total demand for lithium is expected to double or even more than triple by 2025 [2].

An average LIB (lithium-ion battery) contains 5-20\% Co, 5-10\% Ni, 5-7\% Li and $5-10 \%$ of other metals $(\mathrm{Cu}, \mathrm{Al}, \mathrm{Fe}, \mathrm{Cr}$, etc.) [2,18-21]. These values indicate that used 
rechargeable batteries are a high-quality raw material for lithium recovery. Currently, lithium is produced exclusively from brine [22-28] or minerals [29,30]. Traditionally, the primary extraction takes place from lithium-rich solutions, whereby a previous evaporation of the liquid is necessary [31]. The supply of lithium is currently determined by two countries. Together, Chile and Australia account for almost $80 \%$ of global mine funding. In 2025, this situation will shift in favor of Australia, Argentina and Canada. So far, any other resources have been employed to extract lithium, which means that hardly any technologies are available for the recovery from secondary materials. Until now, recycling, and with it the offer from the secondary sector, has not played a significant role in the global range of lithium supply $[5,11,32,33]$. This is caused by large primary resources and reserves and the relatively cheap extraction. The dissipative distribution of lithium and technological requirements of purity for certain applications in the end products also play a major role in this context. Whether, and to what extent, alternative processing technologies for brine and bedrock deposits will be established in the future depends on several factors. In addition to environmental aspects, the long-term stability of the selected processes and production costs play an important role in this framework. It must be noted that lithium production from brine is a time-consuming process when using solar evaporation. Depending on the general conditions, a period of up to 16 months can elapse between brine extraction and further processing of the concentrated solution. Lithium is mainly traded in the form of concentrates (spodumene, petalite) and the two most important intermediate products (lithium carbonate and lithium hydroxide) in different qualities [2].
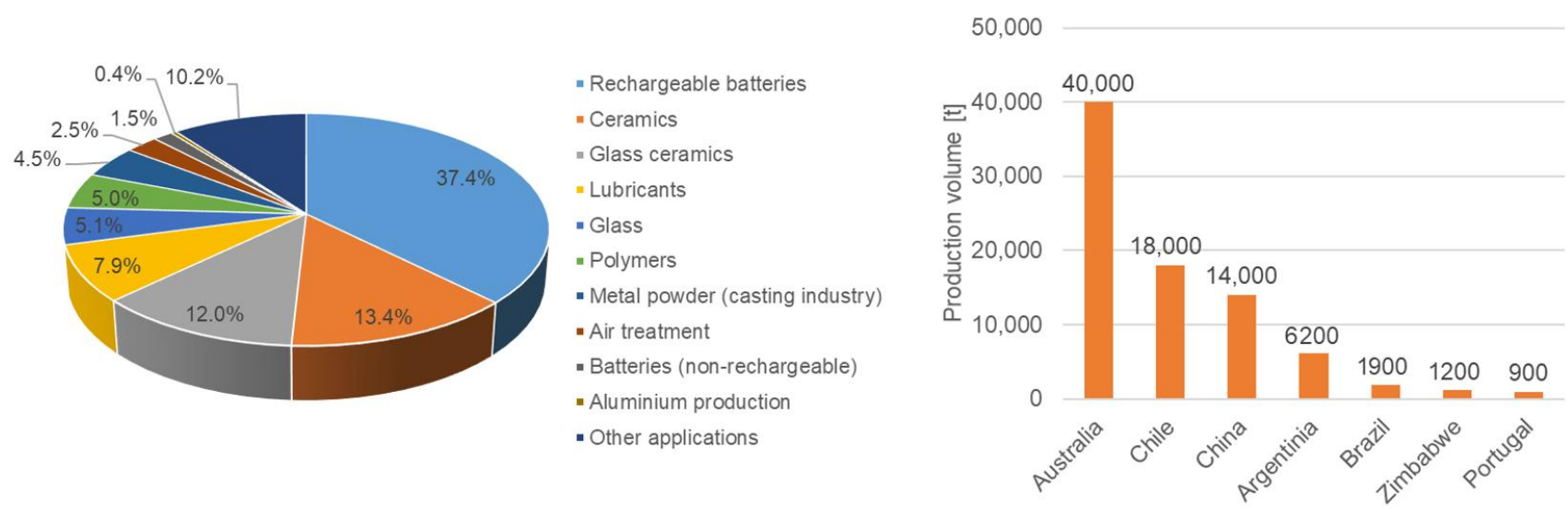

Figure 1. Production volume of lithium by countries for 2020 (left), and the most important application areas of lithium products (right).

In the field of metal recovery from used lithium-ion batteries, the focus is mostly on valuable materials such as cobalt and nickel [5]. Lithium is often recovered as a by-product of poor quality or is not retrieved at all. Due to the character of this element, it often gets extracted in the last step of hydrometallurgical processes, while it forms slags in the known pyrometallurgical methods and is therefore lost to the raw material cycle [34]. In hydrometallurgy, expensive and inefficient recycling methods such as co-precipitation, solvent extraction and electrochemical processes enable only a minor recovery $[35,36]$. The very high salt content of the solutions and the low lithium concentration often prove to be problematic [34]. Classic approaches such as precipitation with sodium carbonate exhibit inadequate results due to the high solubility and the low purity of $\mathrm{Li}_{2} \mathrm{CO}_{3}$ as a product. In addition, consequential to the temperature dependence of the precipitation reaction, high energy consumption and the production of enormous amounts of waste water result $[37,38]$. New approaches work with the precipitation as lithium phosphate, with the choice of compounds based on sodium [39]. Nevertheless, the removal of the excess sodium is often challenging. However, there is still too few data available in this area of hydrometallurgy and further research needs to be done. Additionally, the possibility of 
further processing by roasting with calcium oxide in order to obtain high-quality $\mathrm{LiOH}$ by subsequent leaching in water is exhibited. This processing enables the reuse of this material in lithium-ion batteries; however, due to the high quality standards for the battery production, this technology is currently not supplied [39].

This work is intended to compare the classic method of the precipitation of lithium from synthetic and real leaching liquors gained from lithium-ion batteries with sodium carbonate and with alternative precipitation agents in this area such as sodium phosphate and potassium phosphate. The comparison between a synthetic lithium sulfate solution and a sulfuric acid leaching liquid from the active material of lithium-ion batteries allows the determination of matrix effects in the process step of lithium precipitation by present anions and cations. Furthermore, the correlation of the obtained product to the used type of phosphate should be comprised. In addition to the variation of the process temperature (room temperature to boiling point), a comparison of different molar ratios of the precipitant is conducted in order to finally enable a statement about an efficient process, its parameters and the correlating dependencies.

\section{Materials and Methods}

\subsection{Sample Preparation and Analysis of the Input Materials}

To evaluate the selectivity and efficiency of lithium precipitation with sodium carbonate, sodium phosphate and potassium hydrogen phosphate, a synthetic lithium sulfate solution $\left(\mathrm{Li}_{2} \mathrm{SO}_{4} \cdot \mathrm{H}_{2} \mathrm{O},>99 \%\right.$, p.a., Carl Roth, Karlsruhe, Germany) with a concentration of $10 \mathrm{~g} \cdot \mathrm{L}^{-1}$ lithium was prepared. Additionally, active material from lithium-ion batteries was leached using 2-molar sulfuric acid for four hours at a temperature of $80{ }^{\circ} \mathrm{C}$ and a solid/liquid ratio of $100 \mathrm{~g} \cdot \mathrm{L}^{-1}$. The composition of the active material used was determined by means of sodium peroxide digestion and subsequent analysis by mass spectrometry with inductively coupled plasma (ICP-MS) and is listed in Table 1.

Table 1. Composition of the pyrolyzed active material from lithium-ion batteries used for leaching experiments (determined by ICP-MS: mass spectrometry with inductively coupled plasma).

\begin{tabular}{ccccccccccc}
\hline Element & $\mathbf{L i}$ & $\mathbf{M g}$ & $\mathbf{A l}$ & $\mathbf{S i}$ & $\mathbf{M n}$ & $\mathbf{F e}$ & $\mathbf{C o}$ & $\mathbf{N i}$ & $\mathbf{C u}$ & $\mathrm{Zn}$ \\
\hline [Mass-\%] & 5.2 & 0.06 & 3.7 & $<0.1$ & 7.3 & 0.01 & 6.5 & 22.0 & 4.8 & 0.7 \\
\hline
\end{tabular}

Large amounts of cobalt, nickel, manganese, iron and aluminum could be removed from the leaching solution prepared by means of oxalic acid and sodium hydroxide precipitation, leaving lithium as the main component of the residual leachate $(\mathrm{pH} \sim 9)$. The measurement was carried out using a pH meter (InLab Science, Mettler-Toledo, Vienna, Austria). The stoichiometric amount of precipitant was calculated based on the concentration of lithium in the leaching solution, which was determined via ICP-MS, whereby the corresponding results can be found in Table 2. As shown there, the purified solution contains approx. $5 \mathrm{~g} \cdot \mathrm{L}^{-1}$ of lithium.

Table 2. Composition of the purified leaching solution after precipitation of $\mathrm{Co}, \mathrm{Ni}, \mathrm{Mn}$ and $\mathrm{Al}$ with oxalic acid and sodium hydroxide (measured by ICP-MS).

\begin{tabular}{ccccccccccc}
\hline Element & $\mathbf{L i}$ & $\mathbf{M g}$ & $\mathbf{A l}$ & $\mathbf{S i}$ & $\mathbf{M n}$ & $\mathbf{F e}$ & $\mathbf{C o}$ & $\mathbf{N i}$ & $\mathbf{C u}$ & $\mathbf{Z n}$ \\
\hline$\left[\mathrm{g} \cdot \mathrm{L}^{-1}\right]$ & 5.0 & $<0.01$ & $<0.01$ & $<0.1$ & $<0.01$ & $<0.01$ & 0.03 & 0.23 & $<0.01$ & $<0.01$ \\
\hline
\end{tabular}

For the further processing, the described precipitation media $\left(\mathrm{Na}_{2} \mathrm{CO}_{3}(>99.5 \%\right.$, p.a., ACS, anhydrous, Carl Roth, Karlsruhe, Germany), $\mathrm{Na}_{3} \mathrm{PO}_{4} \cdot 12 \mathrm{H}_{2} \mathrm{O}$ (>98\%, p.a. ACS, Carl Roth, Karlsruhe, Germany)) and also $\mathrm{K}_{2} \mathrm{HPO}_{4} \cdot 3 \mathrm{H}_{2} \mathrm{O}$ (>99\%, p.a., Carl Roth, Karlsruhe, Germany)) were added in solid form to both initial solutions. 


\subsection{Design and Evaluation of Experiments}

The statistical experimental design and evaluation software (MODDE 12.1, Sartorius AG, Goettingen, Germany) was used for the experimental arrangement. Using a full factorial model, eleven individual experiments were carried out for each precipitant, with three center experiments being incorporated for the creation of the statistical model (see Table 3). The variation of the temperature between 25 and $90^{\circ} \mathrm{C}$ and the change of the added amount of precipitant related to the theoretically necessary stoichiometric consumption for the precipitation of the contained lithium (stoichiometric factor between 1 and 3) could thus be realized. The holding period of the precipitation process remained fixed at one hour for the entire test series. The analysis of the residual solutions after vacuum filtration to separate the precipitate was carried out using microwave plasma atomic emission spectrometry (MP-AES), since this measurement method also allows the lithium content in the liquid phase to be determined. With the aid of the statistical test evaluation program, a model could be created for each precipitant and corresponding initial solution. The results are compared with each other in order to define an optimum precipitation process for lithium.

Table 3. Parameters of executed experiments for each precipitation agent (with a fixed holding period for each experiment of $60 \mathrm{~min}$ ).

\begin{tabular}{ccc}
\hline \multirow{2}{*}{ Experiment No. } & Temperature & Stoichiometric Factor \\
\cline { 2 - 3 } & {$\left[{ }^{\circ} \mathbf{C}\right]$} & {$[-]$} \\
\hline 1 & 25 & 1 \\
3 & 60 & 1 \\
4 & 80 & 1 \\
5 & 90 & 1 \\
6 & 25 & 3 \\
7 & 60 & 3 \\
8 & 80 & 3 \\
9 & 90 & 3 \\
10 & 60 & 1 \\
11 & 60 & 1 \\
\hline
\end{tabular}

\subsection{Analysis of the Obtained Product}

In the course of the investigations, recordings of the obtained products could be obtained in a scanning electron microscope. Since no detection of lithium is possible by EDS analysis on the Jeol JSM-IT300 scanning electron microscope, Freising, Germany, which is used for this study, mappings are taken to check the distribution of detectable components such as sulfur and phosphorus.

Additionally, X-ray diffraction (XRD) studies of the phosphatic precipitates were performed to determine the phase distribution in the lithium-containing product. The sample was analyzed by X-ray diffraction in parallel configuration on a Bruker D8 Advance instrument, Vienna, Austria, in the diffraction angle range of 0 to $100^{\circ}$. The step size was set to $0.01^{\circ}$ with an acquisition time of $0.2 \mathrm{~s}$ per measurement point.

\section{Results}

\subsection{Precipitation with $\mathrm{K}_{2} \mathrm{HPO}_{4}$}

When potassium phosphate $\left(\mathrm{K}_{2} \mathrm{HPO}_{4}\right)$ was used as precipitant, quite satisfactory levels of residual lithium concentrations in the solutions were obtained for certain parameter combinations. In principle, a reduction of the lithium concentration by 80 and $60 \%$ starting from the original concentration could be achieved for the synthetic and the authentic starting solution, respectively. For the precipitation process, large amounts of precipitating agent (stoichiometric factor $>2.5$ ) proved to be particularly advantageous, since a considerable part of the lithium already precipitated at low temperatures. This 
statement applies to both the synthetic and the authentic initial solution, although this effect is clearly more pronounced in the former (see Figure 2).
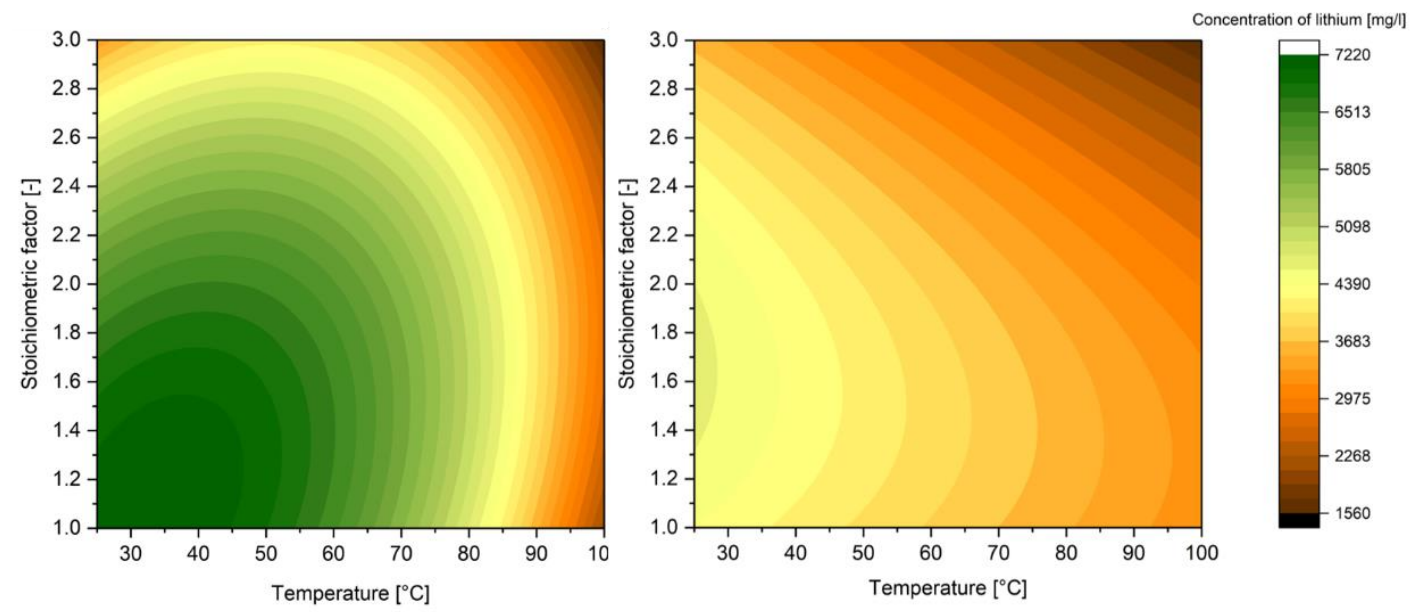

Figure 2. Statistical evaluation of the dissolved residual concentrations in $\mathrm{mg} \cdot \mathrm{L}^{-1}$ of lithium starting from the synthetic (left, $10,000 \mathrm{mg} \cdot \mathrm{L}^{-1}$ ) and authentic (right, $5000 \mathrm{mg} \cdot \mathrm{L}^{-1}$ ) leaching solution using the precipitant $\mathrm{K}_{2} \mathrm{HPO}_{4}$ as a function of temperature and the stoichiometric factor of the precipitant.

The models described for the precipitation process with potassium hydrogen phosphate are based on quadratic model equations. These are given in Equation (1) for the synthetic initial solution and in Equation (2) for the authentic leach liquid. In this case, $\mathrm{T}\left[{ }^{\circ} \mathrm{C}\right]$ reflects the temperature, $x[-]$ the stoichiometric factor of the precipitant and $\mathrm{c}(\mathrm{Li})$ the residual concentration of lithium in the leaching liquid after precipitation, while both quadratic and interaction terms were considered.

$$
\begin{gathered}
c(\mathrm{Li})=5480.8+59.5 \cdot \mathrm{T}+1349.5 \cdot \mathrm{x}-1.3 \cdot \mathrm{T}^{2}-948.8 \cdot \mathrm{x}^{2}+22.5 \cdot \mathrm{T} \cdot \mathrm{x} \\
\quad \mathrm{c}(\mathrm{Li})=3342.8-10.7 \cdot \mathrm{T}+2033.9 \cdot \mathrm{x}-567.4 \cdot \mathrm{x}^{2}-6.1 \cdot \mathrm{T} \cdot \mathrm{x}
\end{gathered}
$$

The evaluation of the results for both the synthetic and the authentic initial solution provides a comparison of the dependencies on temperature and stoichiometric factor in the form of an interaction plot. Figure 3 shows this relationship for the precipitation with $\mathrm{K}_{2} \mathrm{HPO}_{4}$, with the corresponding experimental results from the liquid samples. For the center experiments (three per test series), the precipitation of lithium with $\mathrm{K}_{2} \mathrm{HPO}_{4}$ from the synthetic leaching liquid resulted in a mean value of $4911 \mathrm{mg} \cdot \mathrm{L}^{-1}$ for the residual concentration of lithium in the solution with a standard deviation of $218 \mathrm{mg} \cdot \mathrm{L}^{-1}$. Using the authentic starting solution, a mean value of $4254 \mathrm{mg} \cdot \mathrm{L}^{-1}$ in terms of the lithium concentration could be obtained with a standard deviation of $88 \mathrm{mg} \cdot \mathrm{L}^{-1}$.

\subsection{Precipitation with $\mathrm{Na}_{3} \mathrm{PO}_{4}$}

In comparison, a different pattern emerges for the precipitation of lithium with sodium phosphate, especially considering the synthetic initial solution. The model visualizes a temperature independence; thus, only the stoichiometric factor of the precipitant remains as an influencing parameter. In this way, significant improvements can be made with regard to the energy efficiency of this process. When considering the results from the authentic leaching liquid, a dependence on the process temperature is, nevertheless, evident, albeit much less pronounced than in the case of precipitation with potassium hydrogen phosphate. With a stoichiometric factor of 3 , the temperature exerts hardly any influence, while with lower precipitant quantities at least an experimental temperature of $60^{\circ} \mathrm{C}$ is necessary to enable the efficient precipitation of the alkali metal (see Figure 4). 


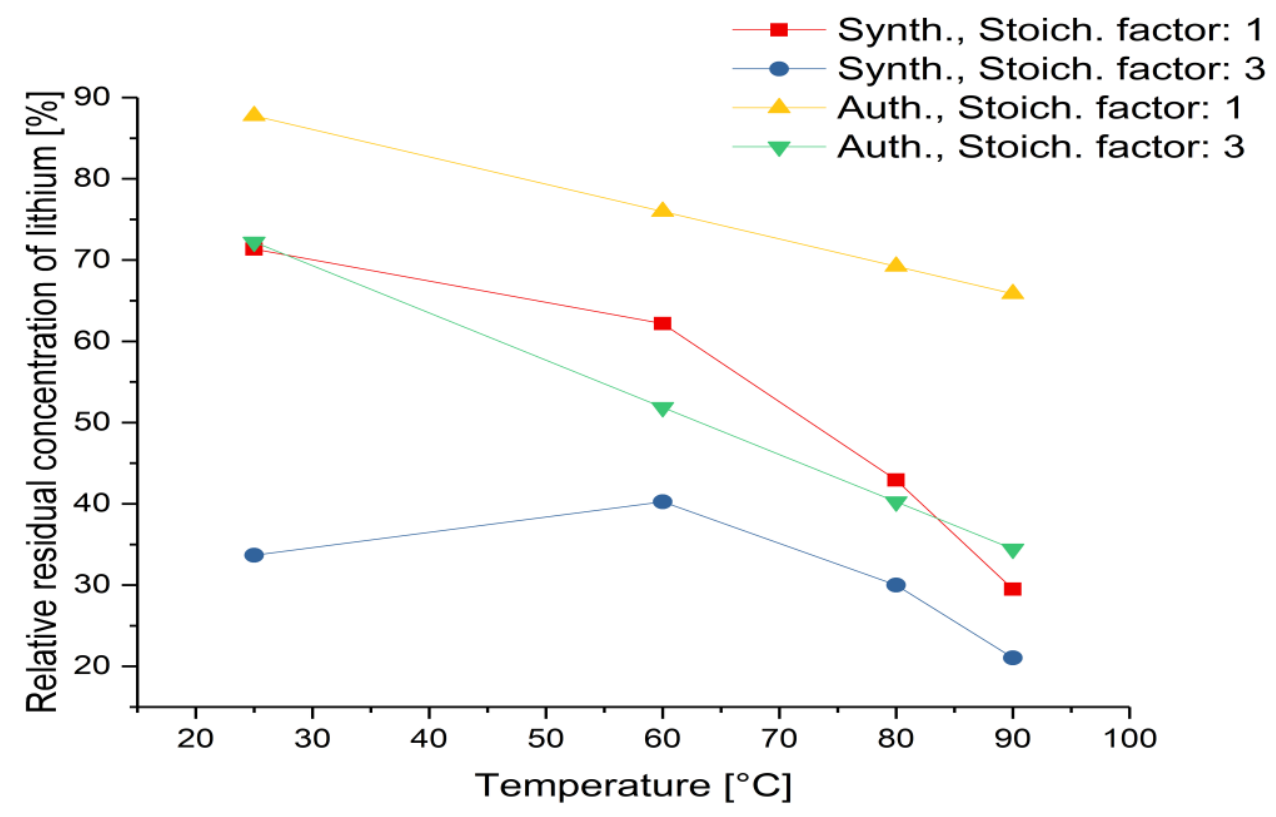

Figure 3. Relative residual concentration of lithium in the samples as a function of temperature and stoichiometric factor (interaction plot of the model) based on the synthetic and authentic leaching solution for the precipitation with $\mathrm{K}_{2} \mathrm{HPO}_{4}$.
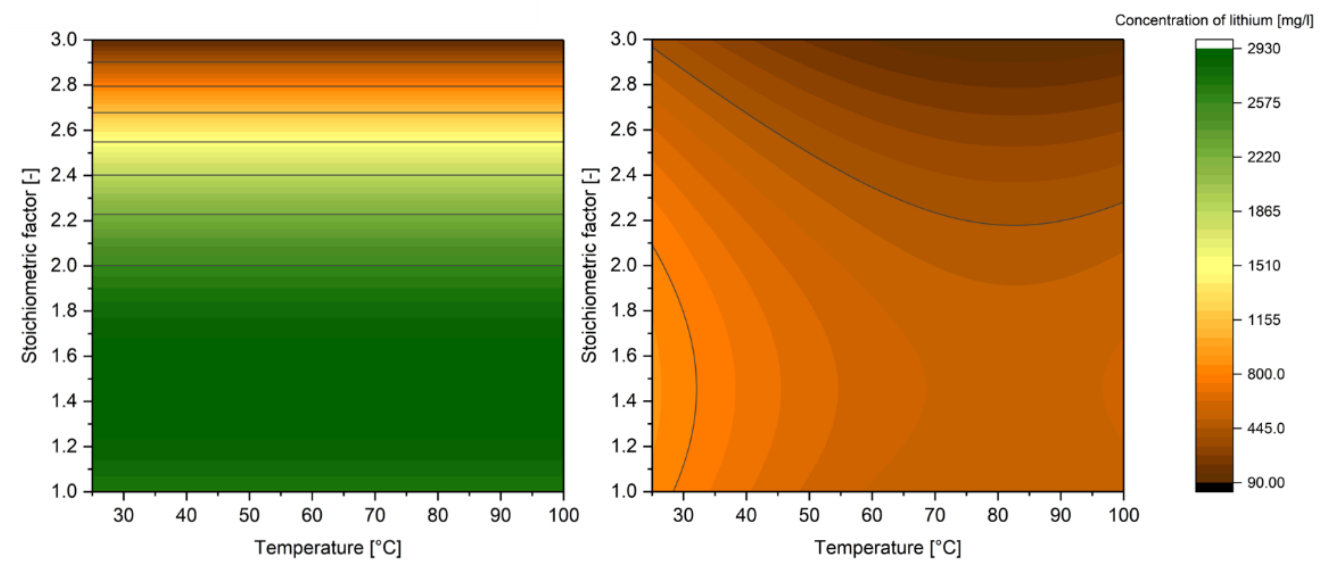

Figure 4. Statistical evaluation of the dissolved residual concentrations in $\mathrm{mg} \cdot \mathrm{L}^{-1}$ of lithium starting from the synthetic (left, 10,000 mg. $\mathrm{L}^{-1}$ ) and authentic (right, $5000 \mathrm{mg} \cdot \mathrm{L}^{-1}$ ) leaching solution using the precipitant $\mathrm{Na}_{3} \mathrm{PO}_{4}$ as a function of temperature and the stoichiometric factor of the precipitant.

The singular dependencies for the model of the synthetic leaching solution can also be seen in the model equation (see Equation (3)), while both quadratic and interaction terms occur for the authentic leach liquid (see Equation (4)).

$$
\begin{gathered}
c(\mathrm{Li})=420.7+3448.7 \cdot \mathrm{x}-1185.5 \cdot \mathrm{x}^{2} \\
\mathrm{c}(\mathrm{Li})=646.3-14.2 \cdot \mathrm{T}+641.2 \cdot \mathrm{x}+0.1 \cdot \mathrm{T}^{2}-186.0 \cdot \mathrm{x}^{2}-1.6 \cdot \mathrm{x} \cdot \mathrm{T}
\end{gathered}
$$

Since the results for the precipitation of lithium with $\mathrm{Na}_{3} \mathrm{PO}_{4}$ starting from a synthetic leaching solution lead to temperature independence, only the interaction plot for the authentic solution is shown in Figure 5. For the center experiments (three per test series), the precipitation of lithium with $\mathrm{Na}_{3} \mathrm{PO}_{4}$ from the synthetic leaching liquid resulted in a mean value of $3683 \mathrm{mg} \cdot \mathrm{L}^{-1}$ for the residual concentration of lithium in the solution with a standard deviation of $357 \mathrm{mg} \cdot \mathrm{L}^{-1}$. Using the authentic starting solution, a mean value of 
$506 \mathrm{mg} \cdot \mathrm{L}^{-1}$ in terms of lithium concentration could be obtained with a standard deviation of $12 \mathrm{mg} \cdot \mathrm{L}^{-1}$.

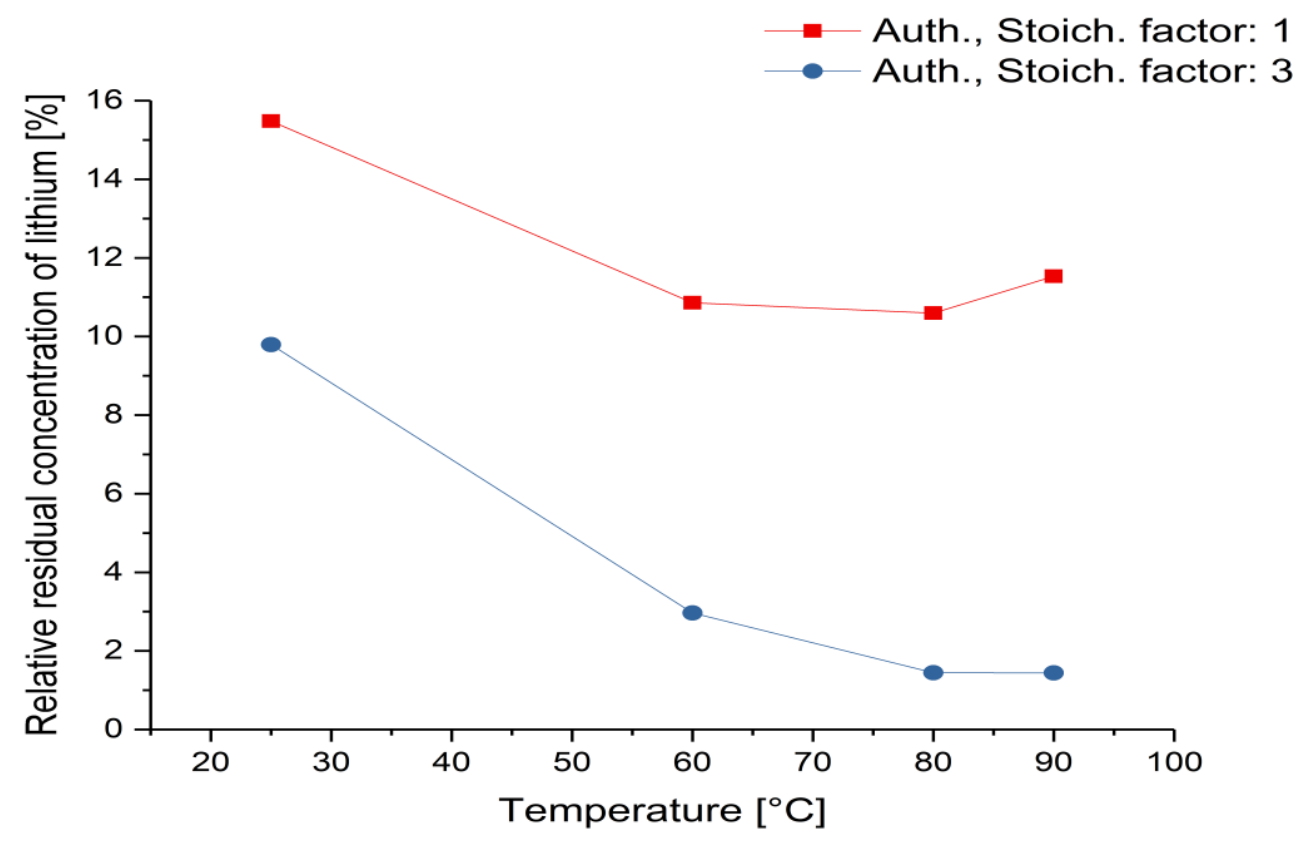

Figure 5. Relative residual concentration of lithium in the samples as a function of temperature and stoichiometric factor (interaction plot of the model) based on the authentic leaching solution for the precipitation with $\mathrm{Na}_{3} \mathrm{PO}_{4}$.

\subsection{Precipitation with $\mathrm{Na}_{2} \mathrm{CO}_{3}$}

Finally, a comparison with the precipitation process, which corresponds to the state of the art in the primary extraction of lithium, is possible. Therefore, also for the precipitation with sodium carbonate from the synthetic and authentic starting solution, statistical models were created and the recovery efficiency was evaluated. In this process, significant deviations of the results for the synthetic and authentic initial solution are shown. When looking at the statistical evaluation for the synthetic liquid, it can be seen that high temperatures lead to sufficient precipitation when a large stoichiometric factor of the precipitant is applied. For the authentic solution, a medium optimum range is found, with even lower amounts of sodium carbonate leading to similar results. In general, however, it must be noted that very low precipitation efficiencies could be achieved, especially for the authentic initial leaching liquid (maximum of 50\%). This may be attributed to the relatively high solubility of $\mathrm{Li}_{2} \mathrm{CO}_{3}$ in aqueous solutions $\left(13.3 \mathrm{~g} \cdot \mathrm{L}^{-1}\right.$ at $\left.20^{\circ} \mathrm{C}\right)$. For this reason, only a small fraction can be precipitated from the low-concentrated lithium solutions. The process could be improved by concentrating the lithium content. Furthermore, Figure 6 also shows the expected fact that the solubility of lithium carbonate decreases with increased temperature $\left(7.2 \mathrm{~g} \mathrm{~L}^{-1}\right.$ at $\left.100{ }^{\circ} \mathrm{C}\right)$, thus achieving a higher recovery efficiency. The observation of the statistical evaluation for the authentic initial solution clearly visualizes that a mere increase in the added precipitant amount does not guarantee an improvement of the precipitation process, but an increase of the temperature is indispensable.

Moreover, in this case, a quadratic model equation considering the interaction parameters was used in both statistical models. Equation (5) represents the corresponding formula for the synthetic initial solution, while Equation (6) shows that of the authentic leaching liquid.

$$
\begin{gathered}
c(\mathrm{Li})=2853.3+11.7 \cdot \mathrm{T}+3153.4 \cdot \mathrm{x}-715.8 \cdot \mathrm{x}^{2}-17.1 \cdot \mathrm{T} \cdot \mathrm{x} \\
\mathrm{c}(\mathrm{Li})=2951.5-40.9 \cdot \mathrm{T}+2277.9 \cdot \mathrm{x}+0.6 \cdot \mathrm{T}^{2}-384.9 \cdot \mathrm{x}^{2}-18.5 \cdot \mathrm{x} \cdot \mathrm{T}
\end{gathered}
$$


Similar to the phosphatic precipitants, interaction plots representing the dependencies between temperature and stoichiometric factor can be generated for precipitation with sodium carbonate (see Figure 7). For the center experiments (three per test series), the precipitation of lithium with $\mathrm{Na}_{2} \mathrm{CO}_{3}$ from the synthetic leaching solution resulted in a mean value of $4927 \mathrm{mg} \cdot \mathrm{L}^{-1}$ for the residual concentration of lithium in the leaching liquid with a standard deviation of $912 \mathrm{mg} \cdot \mathrm{L}^{-1}$. Using the authentic starting solution, a mean value of $2588 \mathrm{mg} \cdot \mathrm{L}^{-1}$ in terms of lithium concentration could be obtained with a standard deviation of $41 \mathrm{mg} \cdot \mathrm{L}^{-1}$.
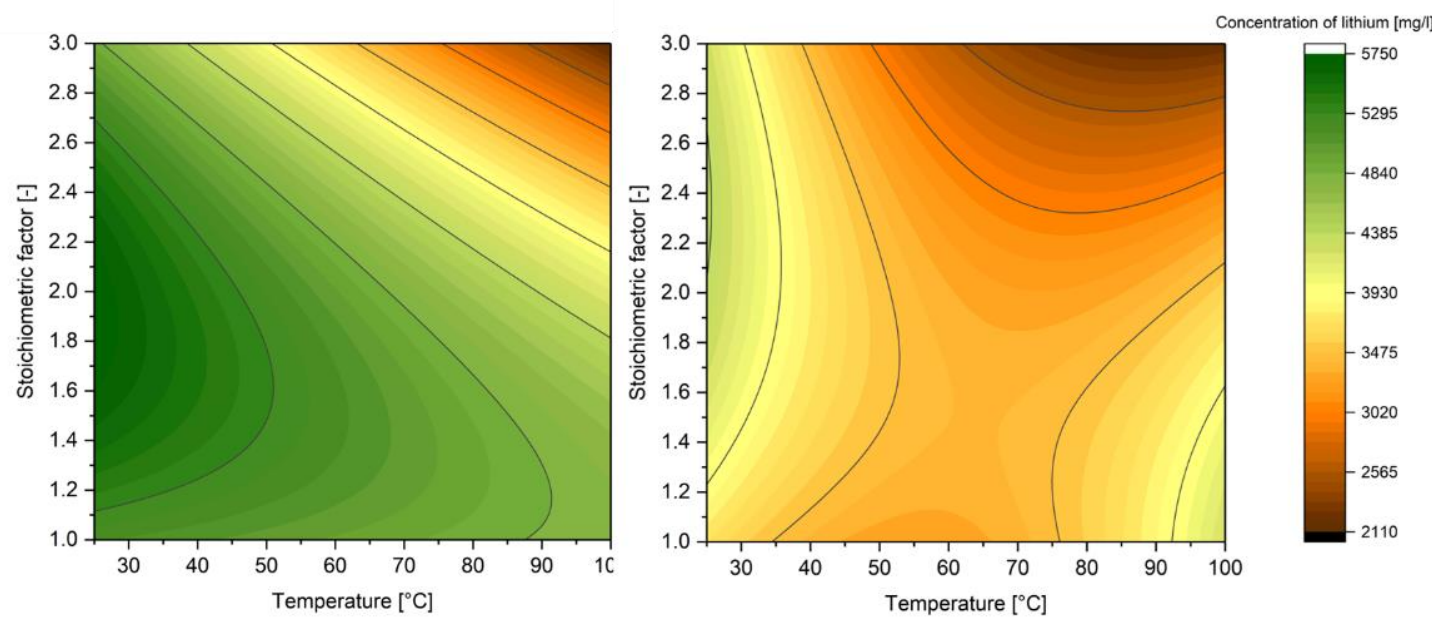

Figure 6. Statistical evaluation of the dissolved residual concentrations in $\mathrm{mg} \cdot \mathrm{L}^{-1}$ of lithium starting from the synthetic (left, 10,000 mg. $\mathrm{L}^{-1}$ ) and authentic (right, $5000 \mathrm{mg} \cdot \mathrm{L}^{-1}$ ) leaching solution using the precipitant $\mathrm{Na}_{2} \mathrm{CO}_{3}$ as a function of temperature and the stoichiometric factor of the precipitant.

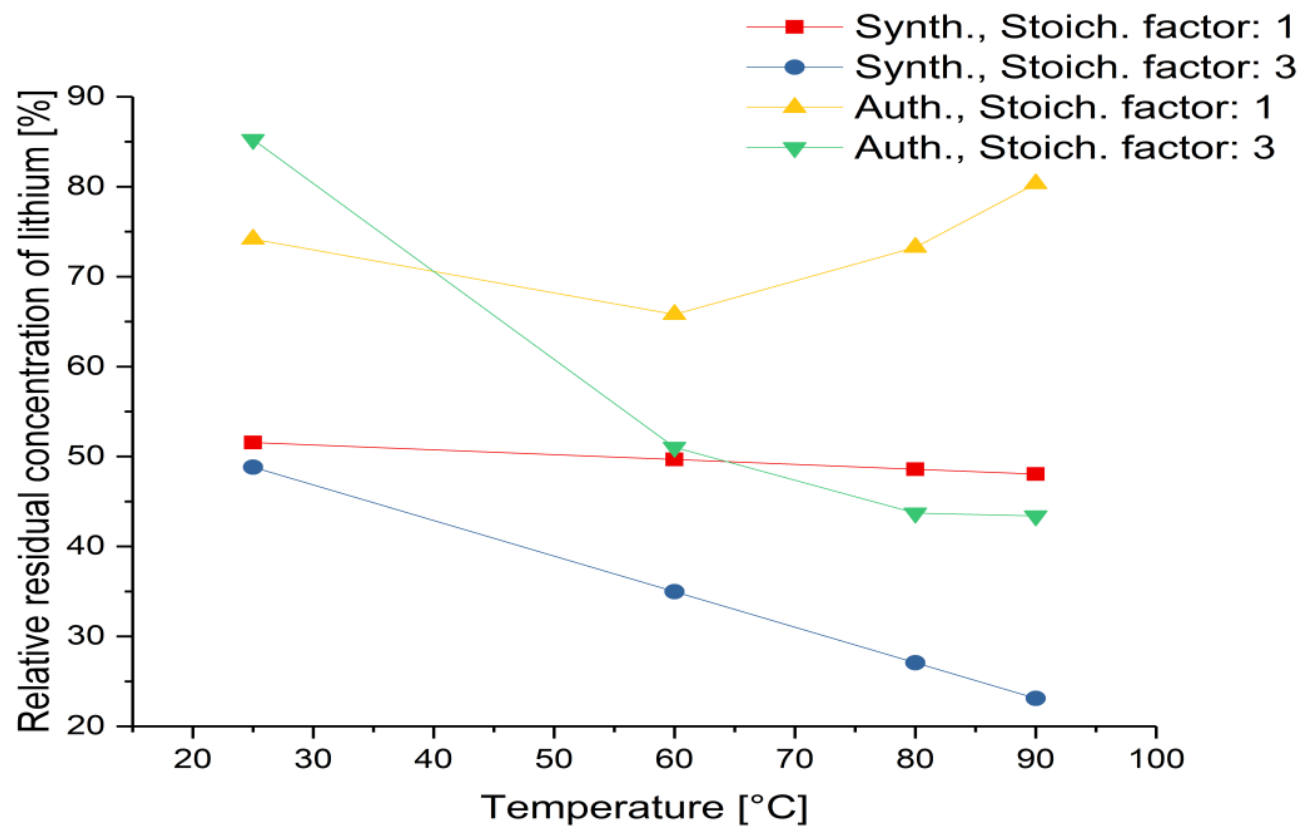

Figure 7. Relative residual concentration of lithium in the samples as a function of temperature and stoichiometric factor (interaction plot of the model) based on the authentic leaching solution for the precipitation with $\mathrm{Na}_{2} \mathrm{CO}_{3}$.

\subsection{Phase Distribution of the Phosphatic Products}

Figure 8 shows the diffractogram for the best parameter combination (determined by the wet chemical analysis) in the precipitation with potassium hydrogen phosphate 
for both the synthetic and the authentic initial solution. The standard peak positions of the individual phases are indicated by colored reference lines in the corresponding diagrams below. For the major part, phases could be assigned to the peaks in the complex diffractogram. It can be seen that, as expected, in the case of the synthetic initial solution, only lithium phosphate $\left(\mathrm{Li}_{3} \mathrm{PO}_{4}\right)$ can be detected in the precipitation product. In the case of the authentic initial solution, any cobalt, nickel and manganese residues are found, but due to the previous precipitation with sodium hydroxide, sufficient $\mathrm{Na}^{+}$ions are present to form sodium sulfate.
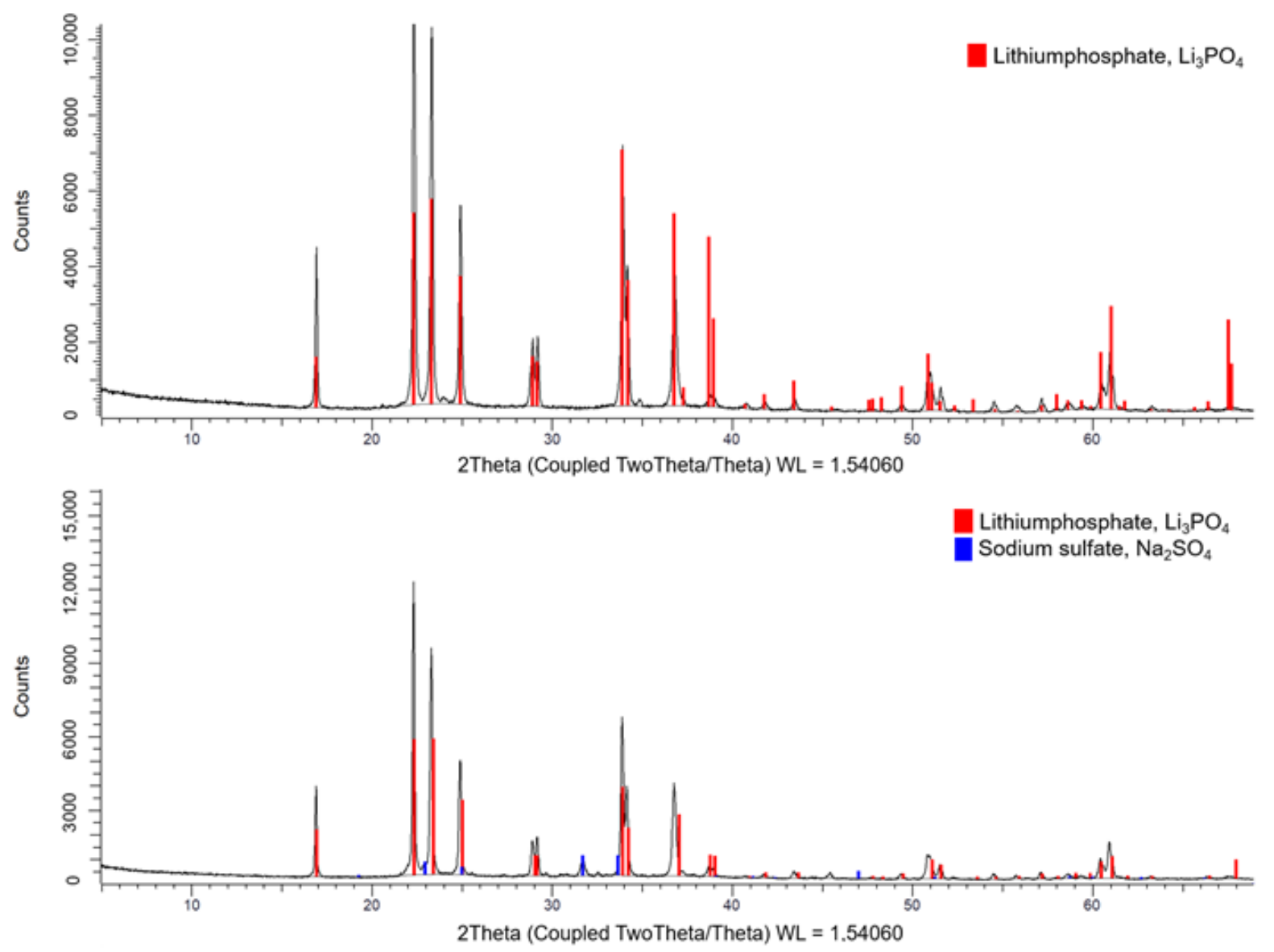

Figure 8. Diffractogram for the precipitation products of the synthetic (top) and authentic (bottom) starting solution using potassium hydrogen phosphate as precipitant.

In comparison, the diffractograms (see Figure 9) for the products from the precipitation with sodium phosphate are to be examined in order to analyze the differences between the phosphatic precipitants. It can be seen in the area of the synthetic initial solution that mainly lithium phosphate could be detected. In addition, a further compound (lithium thiophosphate) appeared in small amounts. In contrast to the precipitation with potassium hydrogen phosphate, sodium oxalate was also detected in the precipitate originating from the authentic starting solution. In this case, the formation of sodium sulfate and sodium oxalate can also be explained by the previous precipitation steps with $\mathrm{NaOH}$ and oxalic acid.

Figure 10 shows the distribution for the precipitation with potassium hydrogen phosphate (left side). The fine precipitate appears very homogeneous, which can also be verified in the SEM, as no enrichments of species can be seen in individual areas. Compared to the phosphate product, a clearly different structure is seen for the precipitation with sodium carbonate. The platy structure also leads to enrichments of individual elements in defined areas, as can be seen in Figure 10 (right side). It follows accordingly that, due to this 
inhomogeneity, the quality of the carbonate precipitate cannot be rated as high as that of the phosphate product.

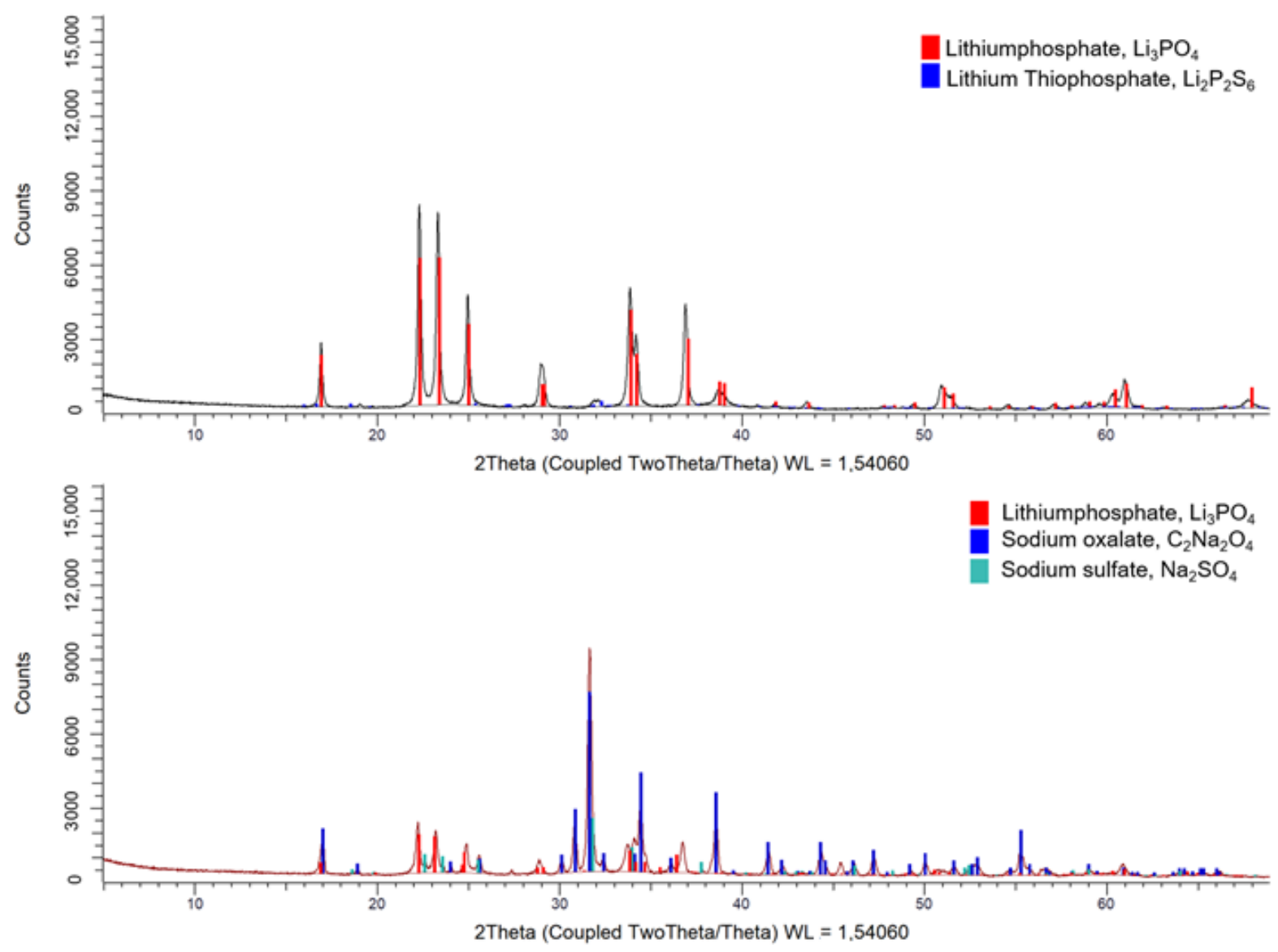

Figure 9. Diffractogram for the precipitation products of the synthetic (top) and authentic (bottom) starting solution using sodium phosphate as precipitant.

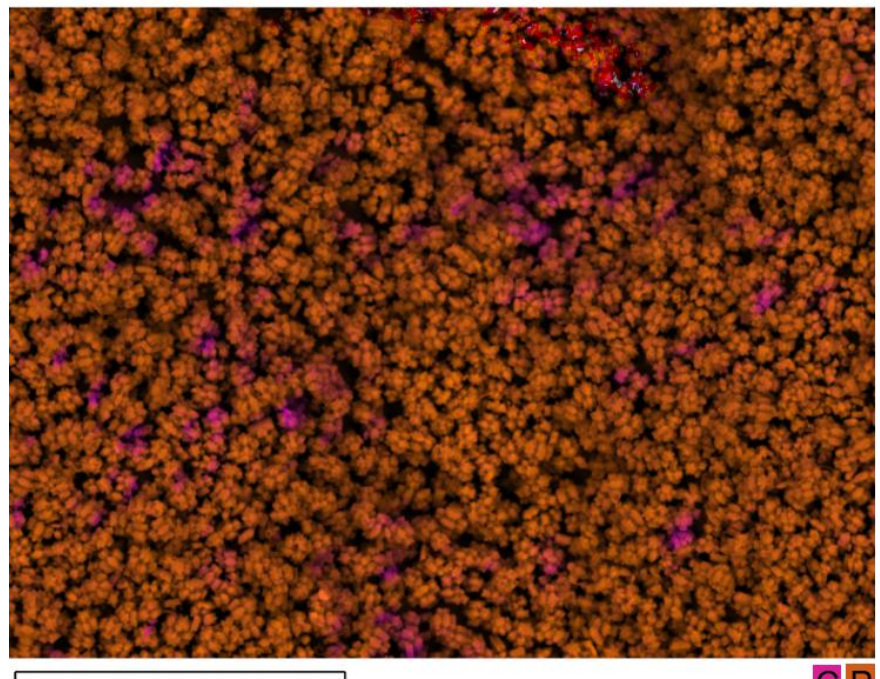

$100 \mu \mathrm{m}$

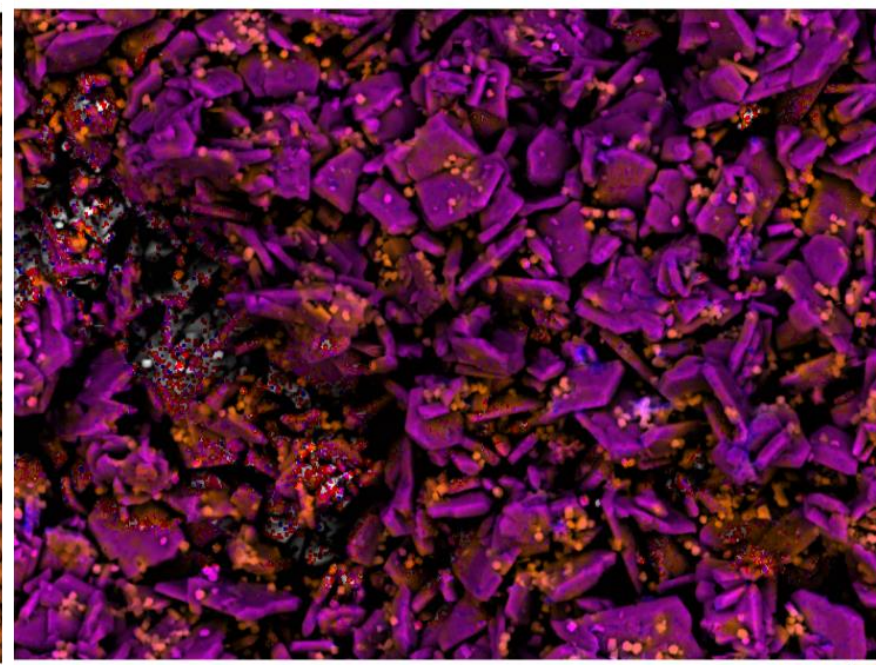

$100 \mu \mathrm{m}$

Figure 10. SEM/EDS (Scanning Electron Microscopy/Energy Dispersive X-ray Spectroscopy) analysis of the products from the precipitation processes with phosphatic (left) and carbonatic (right) precipitants and corresponding element distribution (mapping). 


\section{Discussion}

In summary, it can be stated that in the comparison of precipitants, sodium phosphate in particular stands out as a promising candidate. In this case, starting from both the synthetic and the authentic leaching solution, $95 \%$ of lithium could be recovered. This enables the implementation of a recycling process at a high selective level, with only a minimal amount of the alkali element remaining in the residual solution and thus escaping the raw material cycle. The specific properties of phosphate permit the high solubility of the precipitant in aqueous solutions and the rapid precipitation of the desired compound due to its poorly soluble character. Furthermore, a temperature independence of the precipitation process could be observed when using the synthetic starting solution, while this was not monitored in the case of the authentic leaching liquid. This shows a clear influence of the liquid matrix, since it is loaded with foreign ions such as sodium, oxalates and other impurities. Nevertheless, Figure 4 indicates that the temperature dependence is explicitly less pronounced at temperatures above $60{ }^{\circ} \mathrm{C}$ and again the stoichiometric factor of the precipitant exerts the main influence. This hydrometallurgical process of precipitation enables a feasible and efficient recovery of lithium. Since the recycling of lithium has not been practiced on a large scale to the present due to the low cost of primary resources, the approach shown allows a significant improvement in the availability of raw materials and the recyclability of this critical metal. However, due to the cost of chemicals used in the recycling process, it is currently necessary that regulatory restrictions, especially within the framework of the European Union, drive this field of research and thus promote the implementation of effective recycling processes for lithium.

The usage of potassium phosphate as precipitant is shown to be an alternative method, although significantly lower recovery efficiencies were obtained compared to the sampled sodium-based phosphate compound. Matrix effects could also be observed in this case, as the recovery of lithium from the authentic starting solution is challenging, leaving higher residual concentrations of the alkali metal in the solution.

Lithium recovery in the form of $\mathrm{Li}_{2} \mathrm{CO}_{3}$ cannot be achieved to the same extent and with the same success, as it is the standard with known state-of-the-art processes. The precipitation efficiency for the chosen parameters amounts to about $75 \%$ for the synthetic and $50 \%$ for the authentic starting solution. The use of sodium carbonate as a precipitating agent is, therefore, inefficient in the present series of tests with low lithium concentrations in the liquid. Figure 11 shows a comparison of the correlation and efficiency of all tested precipitants, based on the authentic leaching liquid.

Looking at the obtained products mainly from the processes with phosphatic precipitants, it can be seen that by-products such as sodium sulfate or sodium oxalate are also formed if the authentic leach liquid is used, which could not be detected in the processes with synthetic initial solutions. Thus, a certain load of impurities must also be expected in the recovered product, which, however, strongly depends on the preceding process. Furthermore, these results show that the solution purification process works efficiently, as any cobalt, nickel and manganese residues could be detected in the precipitated products. 


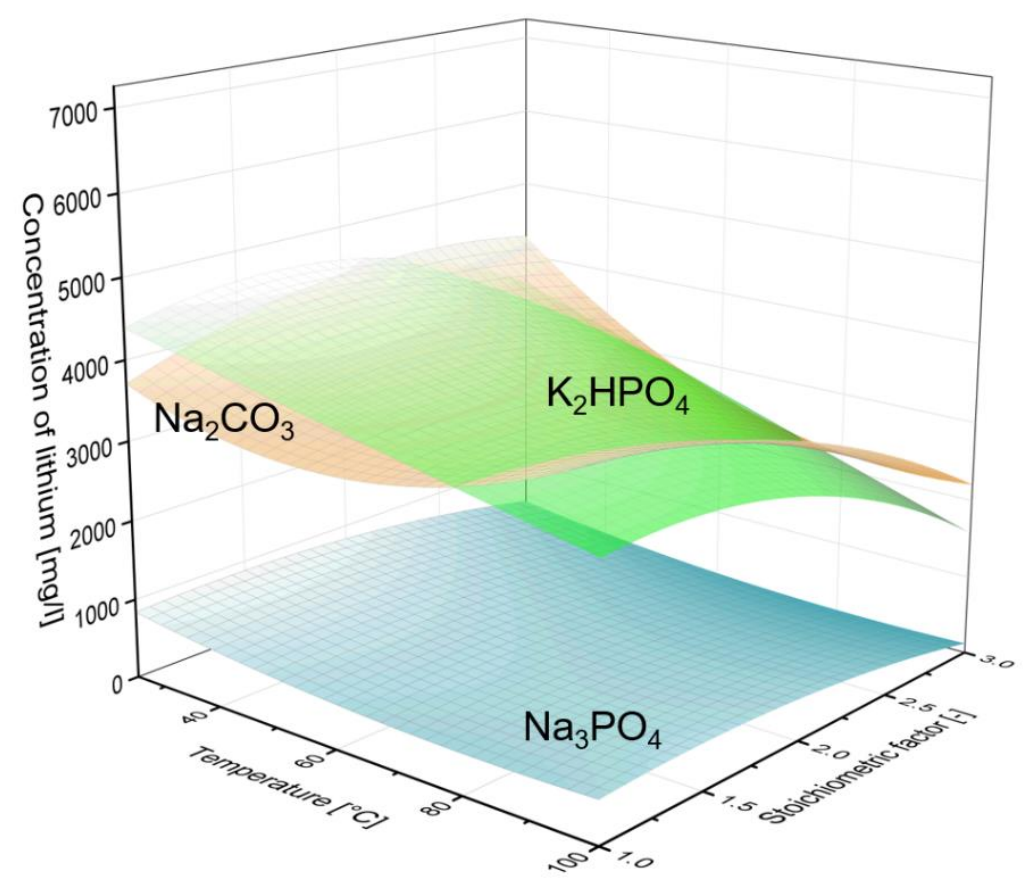

Figure 11. Comparison of the precipitants $\mathrm{Na}_{3} \mathrm{PO}_{4}, \mathrm{~K}_{2} \mathrm{HPO}_{4}$ and $\mathrm{Na}_{2} \mathrm{CO}_{3}$ based on the authentic leaching solution from lithium ion batteries $\left(5000 \mathrm{mg} \cdot \mathrm{L}^{-1}\right)$ as a function of temperature and the stoichiometric factor of the precipitant.

\section{Conclusions}

In summary, the precipitation of lithium from leaching solutions of lithium-ion batteries is a thoroughly complex and still not sufficiently researched field. Due to the complex and frequently varying composition of the active material of lithium-ion batteries, technologies for the recycling of specific components must be adapted and evaluated constantly. Often, only small amounts of lithium are recovered in hydrometallurgical processes, or the alkali metal gets completely removed from the raw material cycle. In the context of this research, precipitation with phosphatic compounds shows great promise, since only low levels of lithium can be detected in the residual solution after the process. Optimization within the framework of a statistical test evaluation also made it possible to work out an optimum parameter combination for the precipitation process as a function of the temperature and the stoichiometric factor of the precipitant. The clarification of the influence of matrix effects shows that an efficient separation of interfering elements in advance is indispensable, but the occurring matrix effects can be well controlled and described. Furthermore, the precipitation product is homogeneously distributed and can be reused as a raw material after further processing.

Author Contributions: Conceptualization, E.G. and H.A.; methodology, E.G.; software, E.G.; validation, E.G., S.L. and H.A.; formal analysis, H.A.; investigation, E.G.; resources, E.G.; data curation, E.G.; writing—original draft preparation, E.G.; writing—review and editing, E.G.; visualization, E.G.; supervision, H.A.; project administration, E.G. All authors have read and agreed to the published version of the manuscript.

Funding: This research received no external funding.

Institutional Review Board Statement: Not applicable.

Informed Consent Statement: Not applicable.

Data Availability Statement: Data sharing is not applicable to this article.

Conflicts of Interest: The authors declare no conflict of interest. 


\section{References}

1. Maxwell, P. Analysing the lithium industry: Demand, supply, and emerging developments. Miner. Econ. 2014, 26, 97-106. [CrossRef]

2. Schmidt, M. Rohstoffrisikobewertung—Lithium; DERA Rohstoffinformationen: Berlin, Germany, 2017 ; Volume 33.

3. Lv, W.; Wang, Z.; Cao, H.; Sun, Y.; Zhang, Y.; Sun, Z. A Critical Review and Analysis on the Recycling of Spent Lithium-Ion Batteries. ACS Sustain. Chem. Eng. 2018, 6, 1504-1521. [CrossRef]

4. Martin, G.; Schneider, A.; Voigt, W.; Bertau, M. Lithium extraction from the mineral zinnwaldite: Part II: Lithium carbonate recovery by direct carbonation of sintered zinnwaldite concentrate. Miner. Eng. 2017, 110, 75-81. [CrossRef]

5. Swain, B. Recovery and recycling of lithium: A review. Sep. Purif. Technol. 2017, 172, 388-403. [CrossRef]

6. Xiao, J.L.; Sun, S.Y.; Song, X.; Li, P.; Yu, J.G. Lithium ion recovery from brine using granulated polyacrylamide-MnO ${ }_{2}$ ion-sieve. Chem. Eng. J. 2015, 279, 659-666. [CrossRef]

7. Hassoun, J.; Lee, K.S.; Sun, Y.K.; Scrosati, B. An advanced lithium ion battery based on high performance electrode materials. J. Am. Chem. Soc. 2011, 133, 3139-3143. [CrossRef]

8. Chi, S.S.; Liu, Y.; Song, W.L.; Fan, L.Z.; Zhang, Q. Prestoring Lithium into Stable 3D Nickel Foam Host as Dendrite-Free Lithium Metal Anode. Adv. Funct. Mater. 2017, 27, 1700348. [CrossRef]

9. U.S. Geological Survey. Mineral Commodity Summaries 2016; U.S. Geological Survey: Reston, VA, USA, 2016 ; p. 202.

10. Hoshino, T. Development of technology for recovering lithium from seawater by electrodialysis using ionic liquid membrane. Fusion Eng. Des. 2013, 88, 2956-2959. [CrossRef]

11. Wang, X.; Gaustad, G.; Babbitt, C.W.; Bailey, C.; Ganter, M.J.; Landi, B.J. Economic and environmental characterization of an evolving Li-ion battery waste stream. J. Environ. Manag. 2014, 135, 126-134. [CrossRef]

12. Singh, J.; Lee, B.-K. Hydrometallurgical recovery of heavy metals from low grade automobile shredder residue (ASR): An application of advanced Fenton process (AFP). J. Environ. Manag. 2015, 161, 1-10. [CrossRef]

13. Tarascon, J.-M. Is lithium the new gold? Nat. Chem. 2010, 2, 510. [CrossRef]

14. Speirs, J.; Contestabile, M.; Houari, Y.; Gross, R. The future of lithium availability for electric vehicle batteries. Renew. Sustain. Energy Rev. 2014, 35, 183-193. [CrossRef]

15. Kuang, G.; Li, H.; Hu, S.; Jin, R.; Liu, S.; Guo, H. Recovery of aluminium and lithium from gypsum residue obtained in the process of lithium extraction from lepidolite. Hydrometallurgy 2015, 157, 214-218. [CrossRef]

16. Li, S.; Leng, D.; Li, W.; Qie, L.; Dong, Z.; Cheng, Z.; Fan, Z. Recent progress in developing Li2S cathodes for Li-S batteries. Energy Storage Mater. 2020, 27, 279-286. [CrossRef]

17. Li, S.; Fan, Z. Encapsulation methods of sulfur particles for lithium-sulfur batteries: A review. Energy Storage Mater. 2021, 34, 107-127. [CrossRef]

18. Sakunthala, A.; Reddy, M.V.; Selvasekarapandian, S.; Chowdari, B.V.R.; Selvin, P.C. Synthesis of compounds, Li(MMn11/6)O4 $(\mathrm{M}=\mathrm{Mn} 1 / 6, \mathrm{Co} 1 / 6,(\mathrm{Co} 1 / 12 \mathrm{Cr} 1 / 12),(\mathrm{Co} 1 / 12 \mathrm{Al1} / 12),(\mathrm{Cr} 1 / 12 \mathrm{Al1} / 12))$ by polymer precursor method and its electrochemical performance for lithium-ion batteries. Electrochim. Acta 2010, 55, 4441-4450. [CrossRef]

19. Lee, S.-Y.; Park, S.-J. Li ion adsorption behaviors of Ni-loaded Li-Mn oxide composites. RSC Adv. 2014, 4, 21899. [CrossRef]

20. Wang, J.; Xie, M.; Wang, H.; Xu, S. Solvent extraction and separation of heavy rare earths from chloride media using nonsymmetric (2,3-dimethylbutyl)(2,4,4'-trimethylpentyl)phosphinic acid. Hydrometallurgy 2017, 167, 39-47. [CrossRef]

21. Tanong, K.; Coudert, L.; Mercier, G.; Blais, J.F. Recovery of metals from a mixture of various spent batteries by a hydrometallurgical process. J. Environ. Manag. 2016, 181, 95-107. [CrossRef] [PubMed]

22. Somrani, A.; Hamzaoui, A.H.; Pontie, M. Study on lithium separation from salt lake brines by nanofiltration (NF) and low pressure reverse osmosis (LPRO). Desalination 2013, 317, 184-192. [CrossRef]

23. Liu, X.; Chen, X.; He, L.; Zhao, Z. Study on extraction of lithium from salt lake brine by membrane electrolysis. Desalination 2015, 376, 35-40. [CrossRef]

24. Jiang, C.; Wang, Y.; Wang, Q.; Feng, H.; Xu, T. Production of Lithium Hydroxide from Lake Brines through Electro-Electrodialysis with Bipolar Membranes (EEDBM). Ind. Eng. Chem. Res. 2014, 53, 6103-6112. [CrossRef]

25. Shi, C.; Jing, Y.; Jia, Y. Solvent extraction of lithium ions by tri-n-butyl phosphate using a room temperature ionic liquid. J. Mol. Liq. 2016, 215, 640-646. [CrossRef]

26. Zhou, Z.; Qin, W.; Fei, W. Extraction Equilibria of Lithium with Tributyl Phosphate in Three Diluents. J. Chem. Eng. Data 2011, 56, 3518-3522. [CrossRef]

27. Chitrakar, R.; Makita, Y.; Ooi, K.; Sonoda, A. Lithium recovery from salt lake brine by $\mathrm{H}_{2} \mathrm{TiO}_{3}$. Dalton Trans. 2014, 43, 8933-8939. [CrossRef] [PubMed]

28. An, J.W.; Kang, D.J.; Tran, K.T.; Kim, M.J.; Lim, T.; Tran, T. Recovery of lithium from Uyuni salar brine. Hydrometallurgy 2012, 117-118, 64-70. [CrossRef]

29. Gabra, G.G.; Torma, A.E.; Olivier, C.A. Pressure leaching of beta-spodumene by sodium chloride. Can. Metall. Q. 1975, 14, 355-359. [CrossRef]

30. Medina, L.F.; El-Naggar, M.M.A.A. An alternative method for the recovery of lithium from spodumene. Metall. Trans. B 1984, 15, 725-726. [CrossRef]

31. Garrett, D.E. Handbook of Lithium and Natural Calcium Chloride; Elsevier: Heidelberg, Germany, 2007. 
32. Vikström, H.; Davidsson, S.; Höök, M. Lithium availability and future production outlooks. Appl. Energy 2013, 110, 252-266. [CrossRef]

33. Sonoc, A.; Jeswiet, J.; Soo, V.K. Opportunities to Improve Recycling of Automotive Lithium Ion Batteries. Procedia CIRP 2015, 29, 752-757. [CrossRef]

34. Hu, J.; Zhang, J.; Li, H.; Chen, Y.; Wang, C. A promising approach for the recovery of high value-added metals from spent lithium-ion batteries. J. Power Sources 2017, 351, 192-199. [CrossRef]

35. Väyrynen, A.; Salminen, J. Lithium ion battery production. J. Chem. Thermodyn. 2012, 46, 80-85. [CrossRef]

36. Pasta, M.; Battistel, A.; la Mantia, F. Batteries for lithium recovery from brines. Energy Environ. Sci. 2012, 5, 9487. [CrossRef]

37. Liu, X.; Zhong, M.; Chen, X.; Zhao, Z. Separating lithium and magnesium in brine by aluminum-based materials. Hydrometallurgy 2018, 176, 73-77. [CrossRef]

38. Meshram, P.; Pandey, B.D.; Mankhand, T.R. Extraction of lithium from primary and secondary sources by pre-treatment, leaching and separation: A comprehensive review. Hydrometallurgy 2014, 150, 192-208. [CrossRef]

39. Chen, X.; Xu, B.; Zhou, T.; Liu, D.; Hu, H.; Fan, S. Separation and recovery of metal values from leaching liquor of mixed-type of spent lithium-ion batteries. Sep. Purif. Technol. 2015, 144, 197-205. [CrossRef] 